\title{
健常者の座位リーチ動作における目標物の位置が 手の運動軌道と体幹運動に与える影響
}

\author{
Influence of Target Location on Hand Trajectories and Trunk Movement during \\ Reaching Tasks Performed by Healthy Young Adults
}

岩本 紘樹 ${ }^{1)}$ 臼田 滋 ${ }^{2)}$

\author{
HiroKI IWAMOTO, RPT ${ }^{1)}$, SHIGERU USUDA, RPT, $\mathrm{PhD}^{2)}$ \\ ${ }^{1)}$ Rehabilitation Center, Hidaka Rehabilitation Hospital: 2204 Yoshiimachi, Maniwa, Takasaki, Gunma 370-2104, Japan \\ TEL+81 27-388-2005E-mail: reha-rhc@hidaka-kai.com \\ ${ }^{2)}$ Gunma University Graduate School of Health Sciences, Department of Rehabilitation
}

Rigakuryoho Kagaku 33(1): 7-12, 2018. Submitted Jun. 28, 2017. Accepted Aug. 23, 2017.

\begin{abstract}
Purpose] The purpose of this study was to investigate the influence of target location on the hand trajectory and the displacements of trunk's center of mass (COM) and the center of pressure (COP) during reaching tasks. [Subjects and Methods] 12 healthy young adult males participated. The reaching tasks were measured using the three-dimensional motion analysis system and force plates. Subjects reached by the right hand to the targets in different three locations; straight ahead, $30^{\circ}$ toward the right side, and $30^{\circ}$ toward left side. Characteristics of the hand trajectory and the displacements of trunk's COM and COP were calculated. [Results] In the straight ahead, the displacements of the COM and COP were longer than the left and right locations. There was not significant difference between the locations in the smoothness and straightness of the hand trajectory. In the straight ahead, the smoothness of the hand trajectory was significantly associated with the COM and COP. [Conclusion] These results suggested that it is possible to manipulate the reaching pattern specific effect by controlling movement time and the range of trunk movement.
\end{abstract}

Key words: reaching movement, kinematics, motion trajectory

要旨：〔目的〕目標物の位置が座位リーチ動作時の手の運動軌道や，体幹質量中心および圧中心移動量に及ぼす影響 を検討すること。【対象と方法】健常成人男性 12 名とした。 三次元動作解析装置と床反力計を使用し, リーチ動作課 題を分析した、リーチの目標物は前方, 左方, 右方の 3 方向とし, リーチ動作時の手の運動軌道の特性と, 体幹質量 中心および圧中心移動量を算出し，それらの関連性を検討した。〔結果〕前方条件では，左方および右方条件に比し て体幹の運動範囲がより大きい傾向を認めた。リーチ軌道の円滑性㧍よび直線性に方向間で差は認めなかった。リー チ軌道の円滑性において前方リーチで体幹運動との関連性を認めた。〔結語〕運動時間や体幹運動距離を制御するこ とで,リーチ動作時の運動特性を操作できる可能性が示唆された。

キーワード : リーチ動作, 運動学的分析, 運動軌道

1) 日高リハビリテーション病院リハビリテーションセンター：群馬県高崎市吉井町馬庭 2204 ( ₹ 370-2104)

TEL 027-388-2005

2) 群馬大学大学院 保健学研究科

受付日 2017 年 6 月 28 日 受理日 2017 年 8 月 23 日 


\section{I.はじめに}

リーチは標的に向かって上肢を伸ばす運動であり，基 本的な腕や手の動作である 1$)$ ，目標となる対象物に手を 伸ばし, 把握する能力は, 摂食, 着衣, 整容などの日常 生活活動（activities of daily living : 以下, ADL）にとっ て重要な運動能力の一つである ${ }^{2)}$.リーチは様々な $\mathrm{ADL}$ 場面で多用される運動であることから，脳血管障 害患者や高齢者において認められるこの能力の低下は, 活動・参加機会の減少に影響を与える。そのため, 理学 療法・リハビリテーション分野においてリーチ能力の評 価および治療は重要なテーマである.

リーチ遂行には上肢機能に加えて，空間内の対象物の 位置を捕捉するための目一頭部一体幹の協調性や, リー チ時の姿勢保持・制御の能力が重要である. 姿勢制御と は空間内で身体を制御し安定性と定位を保つ能力と定義 され，上肢機能に大きな影響を与える ${ }^{3)}$ 。姿勢要求は運 動課題に従って様々に変化し，座位状態でのリーチにお ける姿勢要求は, 立位課題中でのリーチよりも厳しくな く，必要となる筋は主に体幹部の筋であると考えられて いる3). しかし, 起居移動動作や歩行を対象とした動作 分析に比べて, リーチの動作分析の研究報告は少なく, 座位での姿勢制御については立位ほど研究されていない のが現状である．日常生活では多方向で様々な距離への 円滑なリーチが要求されるにもかかわらず, 方向条件の 違いに着目した分析も少ない4-6). また，リーチ動作中 の上肢の運動についての分析は多くなされているものの 上肢運動の円滑性・操作性を保障するべき，体幹の運動 戦略や運動パターンに着目した詳細な運動学的分析研究 の報告は少ないのが現状である 4,6).

健常者における座位リーチ動作の運動軌道の特徵とし て松原ら 7)は，予め目標位置が設定されているような 運動規定に基づくリーチ動作では，手先の軌道が運動開 始時点から停止点まで最短距離をとり，速度や標的が変 わっても不変であることを報告している. Nagasaki ら ${ }^{8)}$ もまた，手関節部の運動軌跡は直線に近似されるとして いる. 日常の様々な活動の主体である上肢による物体へ の関与は, 物体への到達であるリーチ要素と, 実際に物 体を把持する要素に分類され，動作目的に応じて，運動 軌跡や速度などのリーチ要素や把持要素が変化する課題 依存性があることが報告されている9-14)。Dean ら9)は 健常者を対象として，リーチ距離と課題（スイッチを押 す，グラスを掴む）の違いによるリーチ時の体幹・上下 肢間の関係への影響について報告している。課題の変化 は時間的要因に,リーチ距離は時間的・空間的な要因に 影響を与え, リーチ距離が長くなるにつれて体幹と上腕 の分節的な動きの重要性が増加し, 体重を支持するため の下肢活動の役割も増加したとしている。しかしながら 運動軌道を直線性や円滑性の視点より客観的な指標を用
いて分析し，報告している研究は少ない 15-17).

このような現状を整理すると，本来相互に関連するも のと考えられる手の運動軌道特性の客観的な指標と，体 幹の運動戦略との関連性は明らかではない。そのため, 目標物の位置や方向が異なる環境条件によって，座位 リーチ動作における手の運動軌道特性がどのように変化 し，その際の体幹質量中心や圧中心で表現される運動戦 略がどのように運動軌道特性と関連しているかを明らか にする必要がある。

本研究では，健常者の座位リーチ動作を三次元動作解 析により測定し, 目標物の位置の違いが手の運動軌道特 性や，体幹の質量中心および圧中心移動量に与える影響 を明らかにすることを目的とした。

\section{II. 対象と方法}

\section{1. 対象}

健常成人男性 12 名 (平均年齢 23.0 歳, 標準偏差 4.0 歳) を対象とし，利き手は全員右手であった。全例において， リーチ動作の障害となるような重度の視力障害や眩暈, 神経学的疾患の既往はなかった。

本研究は群馬大学医学部疫学研究に関する倫理審査委 員会の承認を得た（承認日：平成 21 年 5 月 12 日，受 付番号：21-1). そのうえで全対象者に研究内容につい て説明を行い，書面にて同意を得て実施した。

\section{2. 方法}

三次元動作解析装置（VICON612，Vicon Motion Systems 社製）および床反力計 4 枚（OR6-6-2000, AMTI 社製）を使用した。三次元動作解析装置では，身 体標点として臨床歩行分析研究会が提唱するDIEF (Data Interface Format File) マーカセットを参考に，右 手関節（橈骨茎状突起），両肩峰中心，両大腿骨大転子 に赤外線反射マーカを貼付した．10台の赤外線カメラ を用いてサンプリング周波数は $60 \mathrm{~Hz}$ で，各身体標点に 貼付した反射マーカの位置を計測した。両肩峰と両大転 子のマーカより Dempsterの計算式を用い頭部と上肢を 含む体幹の質量中心（Center of Mass：以下，COM）を 算出した ${ }^{18)}$. 床反力計上に椅子を設置し，殿部および 両足部を床反力計上に配置して計測した.

開始姿勢は静止座位とし，座面高が調整できる背もた れのない椅子を用いて，大腿支持面が大腿長の半分に， 椅子の高さは下腿長になるように設定した。 また右手掌 は同側大腿部に置き，視線は前方視するように指示し た

課題動作は任意の速度で予め最大リーチ距離に設置さ れた円柱の木片 $(50 \mathrm{~g}$, 直径 $4.5 \mathrm{~cm}$, 高さ $8.5 \mathrm{~cm})$ を 前腕回内外中間位で掴み，静止した後に戻る課題とし た。最大リーチ距離は体幹前傾（股関節屈曲）運動を伴 
い足底が浮かない範囲で到達可能なリーチ距離と定義し た。リーチ課題は右上肢にて行うこととした。目標物の 位置は肩峰の高さで方向の異なる 3 条件とし，右肩峰を 通る矢状面 (前方), 前方から左側に $30^{\circ}$ の位置（左方） 前方から右側に $30^{\circ}$ の位置（右方）とした．計測回数は 3 方向をそれぞれ 3 回とし, 計測順序はランダムとした。 動作習熟を考慮し, 1 回目と 2 回目は練習とし, データ 解析には各方向 3 回目のデータを利用した.

三次元動作解析装置から得られた手関節マーカデータ より, 運動時間 (movement time：以下, MT, 秒), 手 の移動距離 (distance of hand: 以下, DH, mm), MT における手の移動速度の最大時点 (time to peak velocity：以下，TPV，\%), 運動軌道の円滑性を示す 指標として Normalized Jerk Score（以下，NJ)，また直 線性を示す指標として Root Mean Square Error（以下, RMSE）を算出した ${ }^{15,16) . ~}$

$N J=\sqrt{\frac{T^{5}}{D^{2}} \int j^{2}(t) d t}$

$R M S E($ in mm $)=\sqrt{\frac{\sum_{i=1}^{N}\left[\left(x_{a}=x_{i}\right)^{2}+\left(y_{a}=y_{i}\right)^{2}\right]}{N}}$

$\mathrm{j}^{2}=$ jerk（加速度の微分值）の二乗, $\mathrm{T}=\mathrm{MT}$,

$\mathrm{D}=$ 手の移動距離 (DH)

$\mathrm{a}=$ 実際のサンプリング点, $\mathrm{i}=$ 理想的な軌道上の点, $\mathrm{N}=$ サンプリング数

NJ は低值であるほど円滑性が高く，RMSE は低值で あるほど直線性が高いことを示す。

また頭部・上肢を含む体幹の COM の移動距離 (distance of COM : 以下, DCOM, mm) を算出した. 床反力の值は各プレートの合成值を算出し, center of pressure (COP) の移動距離（distance of COP：以下, DCOP）を算出した。機器より得られたデータは $5 \mathrm{~Hz}$ を遮断周波数とするハイカットフィルタリングを実施し
た、また運動の開始・停止点については，手マーカの最 大速度の $5 \%$ を基準とし。その基準を最初に超えた時点 を開始点, その後, 最大值後に低下し，5\%よりも減少 した時点を停止点と定義した ${ }^{19)}$.

各方向間の差の検定には反復測定による一元配置分散 分析, Tukeyの多重比較を用いた。各条件で, 単变量解 析として手の運動軌道に関連する各変数間と, DCOM DCOP との Pearsonの積率相関係数を算出した。 また DH を制御変数とした偏相関係数を算出した。統計処理 には SPSS 11.5J for Windows を使用し，有意水準は $5 \%$ とした。

\section{III. 結 果}

座位リーチ動作における手の運動軌道に関連する各変 数およびDCOM, DCOP の測定結果および分散分析の 結果を表 1 に示す。DCOM と DCOP は前方条件が左方 および右方条件より有意に延長した。

各条件における座位リーチ動作における手の運動軌道 に関する変数および DCOM, DCOP間の相関係数を 表 2 に示す。前方条件において, NJ は MT, RMSE, および DCOM との間にそれぞれ有意な強い正の相関を 認め, TPV との間には有意な強い負の相関を認めた。 また RMSE はDHや，NJ，DCOM，およびDCOP と間 にそれぞれ有意な中等度から強い相関を認め, TPV と の間には有意な中等度の負の相関を認めた。左方条件に おいては，NJ と RMSE 間に有意な強い正の相関を認め たが, NJ およびRMSE については, その他の変数との 有意な相関は認められなかった。右方条件においては, $\mathrm{NJ}$ と RMSE 間に有意な相関は認められなかった。 NJ はMTと, RMSE は DCOM およびDCOP間に有意な 中等度の正の相関を認めた。

また，DHを制御変数として算出した偏相関係数では， 前方条件の NJ と DCOMの間にのみ有意な中等度の正 の相関を認めた，左方および右方条件においては，有意

表 1 各測定項目の結果

\begin{tabular}{lccc}
\hline & 前方 & 左方 & 右方 \\
\hline MT (秒) & $1.48 \pm 0.29$ & $1.46 \pm 0.22$ & $1.41 \pm 0.26$ \\
DH (mm) & $821.8 \pm 76.4$ & $827.8 \pm 68.1$ & $799.2 \pm 65.1$ \\
TPV $(\%)$ & $30.5 \pm 7.1$ & $32.4 \pm 5.6$ & $30.7 \pm 5.0$ \\
NJ & $39.6 \pm 15.2$ & $36.3 \pm 11.0$ & $37.4 \pm 12.8$ \\
RMSE & $146.5 \pm 39.4$ & $143.8 \pm 31.2$ & $142.2 \pm 25.6$ \\
DCOM $(\mathrm{mm}) *$ & $241.1 \pm 44.2$ & $209.1 \pm 43.4^{\#}$ & $204.1 \pm 50.6^{\#}$ \\
DCOP $(\mathrm{mm}) *$ & $191.1 \pm 31.9$ & $159.5 \pm 36.5^{\#}$ & $139.2 \pm 35.1^{\#}$
\end{tabular}

平均值 \pm 標準偏差.

MT: movement time, DH: distance of hand, TPV: time to peak velocisy, NJ: normalized jerk score, RMSE: root mean square error, DCOM: distance of center of mass, DCOP: distance of center of pressure. * : 反復測定一元配置分散分析にて $\mathrm{p}<0.05$, \# : 多重比較にて前方に対して $\mathrm{p}<0.05$. 
表 2 手の運動軌道に関する変数および DCOM, DCOP 間の相関係数

\begin{tabular}{|c|c|c|c|c|c|c|c|}
\hline \multicolumn{8}{|c|}{ 前方条件 } \\
\hline & MT & DH & TPV & NJ & RMSE & DCOM & DCOP \\
\hline MT & - & 0.52 & -0.54 & $0.71^{* *}$ & 0.22 & 0.21 & -0.53 \\
\hline DH & & - & -0.27 & 0.47 & $0.78^{* *}$ & $0.77 * *$ & $0.81 * *$ \\
\hline TPV & & & - & $-0.79 * *$ & $-0.67^{*}$ & $-0.69^{*}$ & -0.48 \\
\hline $\mathrm{NJ}$ & & & & - & $0.71 * *$ & $0.70^{*}$ & 0.51 \\
\hline RMSE & & & & & - & $0.77 * *$ & $0.68^{*}$ \\
\hline DCOM & & & & & & - & $0.90 * *$ \\
\hline DCOP & & & & & & & - \\
\hline \multicolumn{8}{|c|}{ 左方条件 } \\
\hline & MT & DH & TPV & NJ & RMSE & DCOM & DCOP \\
\hline MT & - & -0.46 & 0.16 & 0.43 & 0.33 & 0.39 & 0.13 \\
\hline DH & & - & -0.18 & 0.20 & 0.52 & $0.65^{*}$ & $0.62 *$ \\
\hline TPV & & & - & -0.50 & -0.54 & -0.15 & -0.03 \\
\hline NJ & & & & - & $0.90^{* *}$ & 0.33 & 0.12 \\
\hline RMSE & & & & & - & 0.42 & 0.3 \\
\hline DCOM & & & & & & - & $0.91 * *$ \\
\hline DCOP & & & & & & & - \\
\hline \multicolumn{8}{|c|}{ 右方条件 } \\
\hline & MT & DH & TPV & NJ & RMSE & DCOM & DCOP \\
\hline MT & - & 0.32 & -0.53 & $0.71 * *$ & 0.24 & 0.53 & 0.14 \\
\hline DH & & - & -0.24 & 0.27 & $0.68^{*}$ & $0.83^{* *}$ & $0.87 * *$ \\
\hline TPV & & & - & -0.44 & -0.30 & -0.21 & -0.07 \\
\hline $\mathrm{NJ}$ & & & & - & 0.38 & 0.53 & 0.22 \\
\hline RMSE & & & & & - & $0.61^{*}$ & $0.64^{*}$ \\
\hline DCOM & & & & & & - & $0.84 * *$ \\
\hline DCOP & & & & & & & - \\
\hline
\end{tabular}

MT: movement time, DH: distance of hand, TPV: time to peak velocisy, NJ: normalized jerk score, RMSE: root mean square error, DCOM: distance of center of mass, DCOP: distance of center of pressure.

$*: \mathrm{p}<0.05, * *: \mathrm{p}<0.01$.

表 3 手の移動距離を制御変数とした偏相関係数

\begin{tabular}{|c|c|c|c|c|c|c|}
\hline & \multicolumn{2}{|c|}{ 前方 } & \multicolumn{2}{|c|}{ 左方 } & \multicolumn{2}{|c|}{ 右方 } \\
\hline & DCOM & DCOP & DCOM & DCOP & DCOM & DCOP \\
\hline NJ & $0.60^{*}$ & 0.25 & 0.27 & 0.00 & 0.58 & -0.03 \\
\hline RMSE & 0.44 & 0.12 & 0.14 & -0.03 & 0.11 & 0.13 \\
\hline
\end{tabular}

NJ: normalized jerk score, RMSE: root mean square error,

DCOM: distance of center of mass, DCOP: distance of center of pressure.

$*: \mathrm{p}<0.05$.

な関連性は認められなかった（表 3 )。

\section{IV. 考 察}

軌道波形の特徴を示す TPVについて, Lim ら 13) は リーチ距離が増えることや，対象物の位置がより高くな
ることで，加速期が短縮する傾向は顕著になったと報告 している. Marteniukら 10) は対象物を指示する課題よ りも把握する課題の方がその特徽が認められるとしてお

り, Cristea ${ }^{20)}$ は運動開始〜中間時には速度は増加する

も, 物体を把持するという課題のために, 慎重性が要求 され, 運動時間における減速期が増加していると報告し 
ている。つまりは，動作遂行における難易度が高くなる につれて, TPVは短縮する傾向を示す，本研究の結果 では，TPVは全方向に拉いて 30〜33\%であり，Kudou ら 11) や大堀ら 12) の報告の動作時間における $30 \sim 40 \%$ との報告と一致している. 今回の座位リーチ課題は, 最 大リーチを要求する把持動作課題であり, 比較的難易度 が高いリーチ動作課題であったことが TPV の結果より 推定される.

運動軌道の特性の一要因である円滑性を示す NJ と, 直線性を示す RMSE は，前方㧍よび左方条件で高い相 関（前方; $r=0.71$, 左方 $; r=0.90$ ）を認めて抄り，円 滑性と直線性は概称相互に関連していると思われる。 Balasubramanian ら 21) は円滑性とは, 動きの連続性ま たは非断続性に関連する性質と表現しており，Rand ら 22)は健常成人に扔いて, リーチ時の運動軌道におけ る直線性を最適軌道の一つの指標と報告している。健常 者が最適な軌道を選択しょうとすることで, 本研究の結 果が導かれたものと考える。リーチ方向の違いが両指標 に与える影響について，健常者に扔ける手指抢よび手関 節の運動は，様々な方向にリーチした場合でも直線的な 運動を示す傾向があると示した報告が多い 7,8,20,23,24). 目標物の位置が変わっても，健常者であれば，円滑で直 線的な最適に近いリーチ遂行が可能なものと推察され る。そのため, NJ と RMSEで各方向間に有意差はなく 方向の違いが手関節運動の円滑性抢よび直線性に影響を 与えないことが認められたと考える。

しかしながら，NJとRMSEは各方向条件による関連 性の検討より，その特性が異なる可能性が示唆された。 前方条件と右方条件に㧈いて, NJ は MT との関連性を 認めて抢り（前方；r=0.71，右方；r=0.71）, リーチ動 作の円滑性に対しては時間的な変数との関連性が高いこ とが挙げられる. Chang ら 16) は同様にNJ と MT との 関連性を報告して抢り, 脳卒中者の病性の程度と MT は関連し, 高い精度を要求されるリーチ課題では NJ と MT は関連するとしている。 また，運動の円滑性に関し ては, 課題依存性が強く, 低下が認められる環境として 低速運動や正確性が要求される運動課題の実施時が報告 されている21)。本研究に扔いては体幹運動を伴う最大 リーチが要求される目標物の把持課題という特徵が影響 している可能性がある.

一方，RMSEはNJに比して，前方条件と右方条件に 扮いて，DH との関連性を認めて扮り（前方; $r=0.78$, 右方； $\mathrm{r}=0.68)$, リーチ動作の直線性に対しては空間的 な変数との関連性が高いことが考えられる。しかしなが ら先行研究に扔いては, リーチ距離にかかわらずリーチ の直線性は保障されると報告 7,8) されており, リ一千軌 道の直線性と空間的変数を結びつける根拠は明らかでな い. 把持課題と指示課題という違いなどを踏まえた今後 の検討が必要である。
NJ およびRMSE と DCOM およびDCOP の関連性よ り，前方条件に扔いてDHにかかわらず，体幹の移動量 が大きいほどリーチ動作の円滑性は低下する可能性が示 唆された。健常者での前方へのリーチにおいて, 骨盤の 前傾運動や体幹の前屈運動が認められ, Chateauroux ら 25) は体幹前屈や肩関節の回旋がリーチ距離に大きな 影響を与えるとしている. Shumway-Cookら 3)はリー 千動作の遂行に必要な要素として上肢機能に加えて, リーチ時の姿勢保持・制御の能力が重要と述べている. 座位状態でのリーチに抏いて要求される姿勢制御は, 体 幹機能をより反映することが考えられる。また Kaminski ら 26) は上肢長を越えたリーチ動作では, 体幹 運動が腕の移送の間, 重要な役割を担い, 手の速度と軌 跡の両方に影響を及ぼすことを報告している。目的に向 かう身体部位を目的運動性といい，支える身体部位の姿 勢を支持運動性という機構1) から考えれば, リーチ動 作時の体幹は両者の役割を果たしていると考えられる. 体幹の運動量が増えることは, リーチ動作時の体幹に要 求される負荷が増えることが推察され，手運動の円滑性 を保障することの困難さにつながることが考えられる. 前方条件に比して左右条件で異なる傾向がみられた背景 として, 求められる体幹運動が異なるためとも考えられ る. 小峰ら ${ }^{4)}$ は, 健常者の座位リーチ時に際して体幹 各体節と合成床反力を変化させることで, 目標物の位置 の違いに姿勢調整で対応していると述べて扮り，本研究 により算出・分析した体幹運動に比してより分節的な姿 勢調整が行われている可能性も否定はできない.

本研究の限界として, 軌道分析に扔いて手指の運動要 素を除外しているため, 円滑性や直線性の軌跡分析を行 う他の先行研究との比較に扔いて配慮が必要である。ま た NJ や RMSE の結果の標準偏差は大きく, 対象者が健 常者であることでリーチ課題での運動の自由度の高さを 表している可能性がある，本研究では，動作速度を規定 することに伴う動作習熟などの個人差の観点やマーカ抽 出等の技術的な観点から，動作速度を任意に規定した。 しかし，運動軌道の円滑性や直線性の観点を考慮するう えで動作速度との関連性の分析が重要と考えられ，今後 の検討課題として挙げられる。運動の自由度がより低い 可能性が高い脳卒中や高齢者へと対象を広げた解析を行 うことや, リーチ時間や距離などの課題面の制約を調整 することによる効果検証が今後の臨床応用上重要で ある。

\section{引用文献}

1) 中村隆一, 斎藤 宏, 長崎 浩：基礎運動学，第6版。医 歯薬出版, 2003, pp135-139.

2) Dean CM, Shepherd RB, Adams RD: Sitting balance II: reach direction and thigh support affect the contribution of the lower 
limbs when reaching beyond arm's length in sitting. Gait Posture, 1999, 10: 147-153.

3) Shumway-Cook A, Woollacott MH : モーターコントロール 運動制御の理論から臨床実践へ, 第3 版. 田中 繁, 高橋 明 (監修), 医歯薬出版, 2009, p153, p460.

4) 小峰一宏, 山本澄子：目標物の位置が座位リーチ動作に及 ぼす影響一健常者における体幹機能の分析一. 理学療法科 学, 2013, 28: 195-199.

5) 辻下守弘, 鶴見隆正, 清水ミッシェル・アイズマン・他 : 対象物の位置関係と性質の変化が座位到達動作時の姿勢調 節に及ぼす影響。理学療法学, 2000, 27: 183-191.

6) 今井覚志, 小林 翼, 東海林淳一・他：座位リーチ動作の 運動学的解析. 総合リ八, 2002, 3: 161-166.

7) 松原誠仁, 山元総勝: リハビリテーションにおける上肢リー 千動作の計算モデルとその課題. 保健科学研究誌, 2009, 6: 49-56.

8) Nagasaki H: Asymmetric velocity and acceleration profiles of human arm movements. Exp Brain Res, 1989, 74: 319-326.

9) Dean C, Shepherd R, Adams R: Sitting balance I: trunk-arm coordination and the contribution of the lower limbs during self-paced reaching in sitting. Gait Posture, 1999, 10: 135146.

10) Marteniuk RG, MacKenzie CL, Jeannerod M, et al.: Constraints on human arm movement trajectories. Can J Psychol, 1987, 41: 365-378.

11) Kudoh N, Hattori M, Numata N, et al.: An analysis of spatiotemporal variability during prehension movements: effects of object size and distance. Exp Brain Res, 1997, 117 : 457-464.

12) 大堀具視, 中村眞理子, 石澤光郎：把握動作に与える動作 課題と物体の重量の影響. 作業療法, 2007, 26: 282-289.

13) Lim S, Martin BJ, Chung MK: The effects of target location on temporal coordination of the upper body during $3 \mathrm{D}$ seated reaches considering the range of motion. Int J Ind Ergon, 2004, 34: 395-405.

14) Paulignan $Y$, Frak VG, Toni I, et al.: Influence of object position and size on human prehension movements. Exp Brain
Res, 1997, 114: 226-234.

15) Lemay M, Chouinard S, Richer F, et al.: Huntington's disease affects movement termination. Behav Brain Res, 2008, 187: 153-158.

16) Chang JJ, Wu TI, Wu WL, et al.: Kinematical measure for spastic reaching in children with cerebral palsy. Clin Biomech (Bristol, Avon), 2005, 20: 381-388.

17) 矢島大輔, 大城昌平：時系列デー夕解析による脳血管障 害患者のリーチ動作の運動解析. 理学療法科学, 2008, 23: 765-772.

18) Winter DA: Biomechanics and motor control of human movement, Wiley, 2005.

19) Wagner JM, Rhodes JA, Patten C: Reproducibility and minimal detectable change of three-dimensional kinematic analysis of reaching tasks in people with hemiparesis after stroke. Phys Ther, 2008, 88: 652-663.

20) Cirstea MC, Levin MF: Compensatory strategies for reaching in stroke. Brain, 2000, 123: 940-953.

21) Balasubramanian S, Melendez-Calderon A, Roby-Brami A, et al.: On the analysis of movement smoothness. J Neuroeng Rehabil, 2015, 12: 112-123.

22) Rand MK, Shimansky YP: Two-phase strategy of neural control for planar reaching movements: II--relation to spatiotemporal characteristics of movement trajectory. Exp Brain Res, 2013, 230: 1-13.

23) Bullock D, Grossberg S: Neural dynamics of planned arm movements: emergent invariants and speed-accuracy properties during trajectory formation. Psychol Rev, 1988, 95: 49-90.

24) 長崎 浩: 動作分析のこれから. 理学療法科学, 2003, 18: 147-151.

25) Chateauroux E, Wang X: Effects of age, gender, and target location on seated reach capacity and posture. Hum Factors, 2008, 50: 211-226.

26) Kaminski TR, Bock C, Gentile AM: The coordination between trunk and arm motion during pointing movements. Exp Brain Res, 1995, 106: 457-466. 